\title{
FATORES DE VIRULÊNCIA ASSOCIADOS À FORMAÇÃO DE BIOFILME POR Salmonella enterica: MINIRREVISÃO
}

\author{
MILAN, Camile \\ TIMM, Cláudio Dias ${ }^{1}$.
}

${ }^{1}$ Laboratório de Inspeção de Produtos de Origem Animal, Faculdade de Veterinária, UFPEL.

\section{RESUMO}

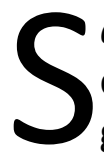

almonella enterica é uma bactéria de importância em saúde pública, responsável por causar salmonelose em humanos através de alimentos contaminados, cursando com gastroenterites. A produção de biofilme por alguns micro-organismos é considerada uma estratégia de sobrevivência em ambientes desfavoráveis, sendo considerado um fator de virulência. O presente trabalho tem por objetivo realizar uma revisão de literatura a fim de elucidar os fatores de virulência associados à formação de biofilme por Salmonella enterica.

Palavras-chave: Contaminação alimentar. Matriz extracelular. Saúde pública.

\section{INTRODUÇÃO}

Bactérias do gênero Salmonella, pertencentes à família Enterobacteriaceae, são bacilos Gram-negativos, anaeróbios facultativos, com temperatura ótima de crescimento de $37^{\circ} \mathrm{C}$. Caracterizam-se por serem oxidase negativas e catalase positivas, além de produzirem ácido sulfídrico e descarboxilarem a lisina, características que auxiliam na identificação bioquímica desses micro-organismos (D'AOUST; MAURER, 2007). Existem duas espécies de Salmonella, sendo que a Salmonella enterica subespécie enterica, especialmente dos sorovares Typhimurium e Enteritidis, é a mais envolvida nos casos de salmonelose em humanos (VUGIA et al., 2004). 
A salmonelose é uma doença de origem alimentar geralmente caracterizada por gastroenterite. A transmissão ao homem ocorre principalmente pela ingestão de carne, principalmente de frango, leite e ovos (FAVRIN et al., 2001).

Biofilme é uma comunidade de micro-organismos sésseis caracterizada por células que se aderem a uma superfície, embebidas em uma matriz extracelular formada por exopolissacarídeos (DONLAN; COSTERTON, 2002). A produção de biofilme pode ser considerada como uma estratégia de sobrevivência dos micro-organismos em ambientes desfavoráveis, podendo constituir fontes crônicas de contaminação microbiana aos alimentos (STEPANOVIC et al., 2004).

Para que os patógenos consigam produzir biofilme, é necessária a produção de alguns fatores, como polissacarídeos extracelulares. Para se fixarem a superfícies sólidas, as células bacterianas utilizam-se desses polímeros, que são secretados pela maioria das espécies (VU et al., 2009).

Outro mecanismo importante produzido por algumas cepas de Salmonella Typhimurium é o regulador CsgD, o qual está implicado na produção de fímbrias agregativas e celulose, presentes no biofilme (RÖMLING et al, 2000). Além disso, alguns genes, como o agf também estão ligados à síntese de fímbrias que auxiliam na adesão das bactérias a superfícies (COLLINSON et al., 1996).

A presença de micro-organismos formadores de biofilme na indústria de alimentos constitui um grande problema, pelo fato de se fixarem firmemente em diferentes superfícies, dificultando sua remoção e consequentemente contaminando os produtos e deteriorando equipamentos (VIANA, 2006). As bactérias, quando contaminam o alimento, alteram suas características, levando a perdas econômicas. No entanto, o problema mais grave está relacionado à saúde pública, pois o biofilme pode veicular micro-organismos patogênicos que podem causar doenças transmitidas por alimentos (DTA) (CAIXETA, 2008).

O objetivo dessa revisão é explanar fatores relevantes na formação de biofilme por Salmonella enterica. 


\section{FATORES ASSOCIADOS À FORMAÇÃO DE BIOFILME}

\section{Polissacarídeos extracelulares, fímbrias e celulose bacteriana}

O biofilme é caracterizado por uma complexa estrutura formada basicamente por proteínas, íons e polissacarídeos (BRANDA et al., 2005). Essa estrutura adere-se em superfícies e, em seguida, ocorre a maturação do mesmo, caracterizada por um rearranjo na arquitetura, com o desenvolvimento de uma estrutura mais complexa, com formação de canais, poros e a redistribuição das bactérias presentes (STOODLEY et al., 2002). É nessa fase que se dá a produção de grandes quantidades de exopolímeros que protegem o biofilme, conferindo estabilidade e resistência (BRYERS; FLETCHER, 2000).

Os polissacarídeos são responsáveis pelo estabelecimento do biofilme, promovendo a interação entre as células bacterianas (BRANDA et al., 2005). A proporção desses componentes nos biofilmes varia de $50-90 \%$ da matéria orgânica total (DONLAN, 2002). A síntese dos polissacarídeos bacterianos ocorre intracelularmente, utilizando açúcares nucleotídeos difosfatados, que podem ser produzidos durante todo o crescimento bacteriano ou somente durante a fase logarítmica (SOUZA; GARCIA-CRUZ, 2004). Essa síntese geralmente ocorre em resposta às mudanças das condições ambientais (CAIAZZA; O'TOOLE, 2004) ou por mudanças no metabolismo da bactéria (WHITE et al., 2010). Esse componente age como fator de adesão e barreira, auxiliando a célula bacteriana a resistir a condições de estresse, como diminuição de nutrientes e condições ambientais adversas (CAIXETA, 2008).

O lipopolissacarídeo (LPS) presente na membrana externa de bactérias Gram-negativas desempenha um papel importante na fixação inicial da bactéria em superfícies, que se aderem mais rapidamente quando há maior hidrofobicidade da superfície celular (BOWER et al., 1996).

Fímbrias agregativas são apêndices de membrana compostos por uma proteína estrutural (pilina), presentes na superfície de bactérias Gram-negativas (TORTORA et al., 2000). São estruturas que possuem resíduos hidrofóbicos, que auxiliam na adesão e colonização bacteriana às superfícies, sendo importantes na persistência ambiental, colonização celular e formação de biofilmes (GIBSON et al., 2007). Essas estruturas, quando presentes, ligam a 
célula bacteriana ao substrato, auxiliando na maior fixação do biofilme em superfícies e dificultando a sua remoção (CAIXETA, 2008).

As fímbrias, juntamente com polissacarídeos e flagelos, estão diretamente envolvidas com o grau de hidrofobicidade das células bacterianas (FLACH et al., 2005). Quanto maior a hidrofobicidade celular, mais facilitada estará a adesão inicial às superfícies, principalmente hidrofóbicas, como o aço inoxidável (BOARI, 2008). Essas fímbrias agregativas, também chamadas de fímbrias de curli, são sintetizadas a partir dos genes agf, que são organizados em 2 operons (agfBAC e agfDEFG) (COLLINSON et al., 1996). A produção das fímbrias é coregulada pelo gene $a g f D$, que também atua indiretamente no gene $a d r A$, a fim de regular a produção de celulose (RÖMLING, 2002; ZAKIKHANY et al., 2010).

A celulose bacteriana é outro componente importante no desenvolvimento do biofilme controlado pelos genes $b c s A, b c s B, b c s Z$ e $b c s C$, que são os responsáveis pela sua síntese (ZAKIKHANY et al., 2010). Quando a síntese de celulose é associada à presença de fímbrias agregativas, pode-se observar uma morfologia característica da Salmonella enterica em ágar Luria Bertani. Essa característica, conhecida como morfologia rdar (red, dray e rough), faz com que as colônias no meio de cultura apresentem-se vermelhas, secas e ásperas (GERSTEL; RÖMLING, 2003; SOLANO et al., 2002; ZOGAJ et al., 2001). Essa morfologia proporciona maior resistência à dessecação e processos de desinfecção, aumentando a sobrevivência dos micro-organismos (ANRIANY et al., 2001; SCHER et al., 2005; WHITE et al., 2006).

CsgD é o regulador responsável pela morfologia rdar, ativando diretamente a transcrição do operon $\operatorname{csg} B A$, que codifica os componentes estruturais das fímbrias de curli (BROMBACHER et al., 2003). O efeito do CsgD na produção de celulose se dá pela ativação da transcrição da diguanylato ciclase (AdrA) a qual gera um ativador alostérico da celulose sintase (ZOGAJ et al., 2001).

CsgD é considerado regulador chave que, além de ser responsável pela ativação do operon csg, também modula a expressão de um conjunto de genes envolvidos na adaptação celular fisiológica para a manutenção do biofilme (BOUGDOUR et al., 2004). A expressão do regulador CsgD é controlada rigidamente pelas condições ambientais e proteínas 
reguladoras globais, como OmpR (GERSTEL; RÖMLING, 2003), considerada um ativador da expressão de genes (FORST et al., 1987).

A expressão de todos os genes envolvidos é necessária para a maturação do biofilme, podendo ser considerada um ponto de controle na sua formação. Este controle ocorre, em Salmonella, pela regulação da produção dos constituintes principais dessa matriz e do controle da transição entre células planctônicas e células com comportamentos multicelulares diferenciados (GERSTEL; RÖMLING, 2001), levando à formação de uma rede altamente hidrofóbica com células compactadas em uma matriz rígida (ZAKIKHANY et al., 2010).

É importante ressaltar que a expressão dos genes responsáveis pela formação do biofilme é altamente regulada por diferentes estímulos ambientais que levam a bactéria ao estresse, como temperatura, tensão de oxigênio, nutrientes, osmolaridade e pH (GERSTEL; RÖMLING, 2001).

Os fatores de virulência associados à formação de biofilme por Salmonella enterica ainda não estão bem elucidados, apesar de já se saber que alguns genes possuem relação direta com a produção dessa estrutura. Logo, deve-se ter atenção na indústria alimentícia, pelo perigo que pode causar através da contaminação alimentar.

\section{CONCLUSÃO}

Salmonella enterica é capaz de formar biofilme, e, para isso, expressa fatores de patogenicidade para se aderir em superfícies e conseguir produzir essa matriz extracelular. Grande parte dessa formação se dá por estruturas presentes na superfície da bactéria, as quais estão associadas à expressão de genes específicos. 


\section{VIRULENCE FACTORS ASSOCIATED WITH BIOFILM FORMATION BY Salmonella enterica: MINI-REVIEW}

\section{ABSTRACT}

almonella enterica is a bacterium of public health significance, responsible for causing salmonellosis in humans through contaminated food, coursing with gastroenteritis. The biofilm production by some microorganisms is considered a strategy for survival in harsh environments, and it is considered a virulence factor. This paper aims to carry out a literature review in order to elucidate the virulence factors associated with biofilm formation by Salmonella enterica.

Keywords: Food contamination. Extracellular matrix. Public health.

\section{FACTORES DE VIRULENCIA ASOCIADOS A LA FORMACIÓN DE BIOPELÍCULAS POR Salmonella enterica: MINI-REVISIÓN}

\section{RESUMEN}

$\mathrm{S}$ almonella enterica es una bacteria de importancia para la salud pública, responsable por causar salmonelosis en los seres humanos a través de alimentos contaminados, que cursa con gastroenteritis. La producción de biofilm por algunos microorganismos se considera una estrategia de supervivencia en ambientes hostiles, y se considera un factor de virulencia. Este trabajo tiene como objetivo hacer una revisión de literatura con el fin de dilucidar los factores de virulencia asociados con la formación de biopelículas por Salmonella enterica.

Palabras clave: Contaminación de los alimentos. Matriz extracelular. Salud pública.

\section{REFERÊNCIAS}

ANRIANY, Y. A.; WEINER, R. M.; JOHNSON, J. A.; et al. Salmonella enterica serovar Typhimurium DT104 displays a rugose phenotype. Applied and Environmental Microbiology, v. 67, p. 4048-4056, 2001.

BOARI, C. A. Formação de biofilme em aço inoxidável por Aeromonas hydrophila e Staphylococcus aureus sob diferentes condições de cultivo. Lavras: UFLA, 2008. 80p. Tese (Doutorado em Ciência dos Alimentos) - Universidade Federal de Lavras, 2008. 
BOUGDOUR, A.; LELONG, C.; GEISELMANN, J. Crl, a low temperature-induced protein in Escherichia coli that binds directly to the stationary phase sigma subunit of RNA polymerase. Journal of Biological Chemistry, v. 279, p. 19540-19550, 2004.

BOWER, C. K.; MCGUIRE, J.; DAESCHEL, M. A. The adhesionand detachmentof bacteria and spores on food-contact surfaces. Trends in Food Science and Technology, v. 7, p. 152-157, 1996.

BRANDA, S. S.; VIK, A.; FRIEDMAN, L.; et al. Biofilms: the matrix revisited. Trends in Microbiology, v. 13, p. 20-26, 2005.

BROMBACHER, E.; DOREL, C.; ZEHNDER, A. J.; et al. The curli biosynthesis regulator CsgD coordinates the expression of both positive and negative determinants for biofilm formation in Escherichia coli. Microbiology, v. 149, p. 2847-2857, 2003.

BRYERS, J. D.; FLETCHER, M. Biofilm formation and persistence. In: BRYERS, J. D. Biofilms II Process Analysis and Applications. New York: John Wiley \& Sons, 2000, p. 45-88.

CAIXETA, D. S. Sanificantes químicos no controle de biofilmes formados por duas espécies de Pseudomonas em superfície de aço inoxidável. Lavras: UFLA, 2008. 75p. Dissertação (Mestrado em Microbiologia Agrícola) - Universidade Federal de Lavras, 2008.

CAIAZZA, N. C.; O'TOOLE, G. A. SadB is required for the transition from reversible to irreversible attachment during biofilm formation by Pseudomonas aeruginosa PA14. Journal of Bacteriology, v. 186, p. 4476-4485, 2004.

COLLINSON, S. K.; CLOUTHIER, S. C.; DORAN, J. L.; et al. Salmonella Enteritidis agfBAC operon encoding thin, aggregative fimbriae. Journal of Bacteriology, v. 178, p. 662-667, 1996.

D'AOUST, J. Y.; MAURER, J. Salmonella species. In: DOYLE, M. P.; BEUCHAT, L.R. (Eds). Food Microbiology: Fundamentals and Frontiers. Washington D.C.: ASM Press, 2007, p. 187-236.

DONLAN, R. M. Biofilms: Microbial life on surfaces. Emerging Infectious Diseases, v. 8, p. 881-890, 2002.

DONLAN, R. M; COSTERTON, J. M. Biofilms: Survival Mechanisms of clinically Relevant Microorganisms. Clinical Microbiology Reviews, v. 15, p. 167-193, 2002.

FAVRIN, S. J.; JASSIM, S. A.; GRIFFITHS, M. W. Development and Optimization of a novel immunomagnetic separation - bacteriophage assay for detection of Salmonella enterica serovar Enteritidis in broth. Applied and Environmental Microbiology, v. 67, n. 7, p. 217224, 2001. 
FLACH, J.; KARNOPP, C.; CORÇÃO, G. Biofilmes formados em matéria-prima em contato com leite: fatores de virulência envolvidos. Acta Scientiae Veterinariae, v. 33, n. 3, p. 291-296, 2005.

FORST, S.; COMEAU, D.; NORIOKA, S.; et al. Localization and membrane topology of EnvZ, a protein involved in osmoregulation of OmpF and $\mathrm{OmpC}$ in Escherichia coli. Journal of Biological Chemistry, v. 262, p. 16433-16438, 1987.

GERSTEL, U.; RÖMLING, U. Oxygen tension and nutrient starvation are major signals that regulate agfD promoter activity and expression of the multicellular morphotype in Salmonella Typhimurium. Environmental Microbiology, v. 3, n. 10, p. 638-648, 2001.

GERSTEL, U.; RÖMLING, U. The csgD promoter, a control unit for biofilm formation in Salmonella Typhimurium. Research in Microbiology, v. 154, p. 659-667, 2003.

GIBSON, D. L.; WHITE, A. P.; RAJOTTE, C. M.; et al. AgfC and AgfE facilitate extracellular thin aggregative fimbriae synthesis in Salmonella Enteritidis. Society for General Microbiology, v. 153, p. 1131-1140, 2007.

RÖMLING, U. Molecular biology of cellulose production in bacteria. Research in Microbiology, v. 153, p. 205-212, 2002.

RÖMLING, U.; ROHDE, M.; OLSEN, A.; et al. AgfD, the checkpoint of multicellular and aggregative behaviour in Salmonella Typhimurium regulates at least two independent pathways. Molecular Microbiology, v. 36, p. 10-23, 2000.

SCHER. K.; RÖMLING, U.; YARON, S. Effect of heat, acidification, and chlorination on Salmonella enterica serovar Typhimurium cells in a biofilm formed at the air-liquid interface. Applied and Environmental Microbiology, v. 71, p. 1163-1168, 2005.

SOLANO, C.; GARCIA, B.; VALLE, J.; et al. Genetic analysis of Salmonella Enteritidis biofilm formation: Critical role of cellulose. Molecular Microbiology, v. 43, p. 793-808, 2002.

SOUZA, D. M.; GARCIA-CRUZ, C. H. Produção fermentativa de polissacarídeos extracelulares por bactérias. Semina: Ciências Agrárias, Londrina, v. 25, n. 4, p. 331-340, out./dez. 2004.

STEPANOVIC, S.; CIRCOVIC, I. RANIN L.; et al. Biofilm formation by Salmonella spp. and Listeria monocytogenes on plastic surface. Letters in Applied Microbiology, v. 38, p. 428432, 2004.

STOODLEY, P.; SAUER, K.; DAVIES, D. G.; et al. Biofilms as complex differentiated. Annual Review Microbiology, v. 56, p. 187-209, 2002.

TORTORA, G. J; FUNKE, B. R.; CASE, C. L. Microbiologia. 6. ed. Porto Alegre: ARTMED, 2000. $83 p$. 
VIANA, E. S. Moléculas sinalizadoras de quorum sensing em biofilmes formados por bactérias psicrotróficas isoladas de leite. Viçosa: UFV, 2006. 159p. Tese (Doutorado em Microbiologia Agrícola) - Universidade Federal de Viçosa, 2006.

VU, B. M.; CHEN, R. J; CRAWFORD, E. P. Bacterial extracellular polysaccharides involved in biofilm formation. Molecules, v. 14, p. 2535-2554, 2009.

VUGIA, D. J.; SAMUEL, M.; FARLEY, M. M.; et al. Invasive Salmonella infections in the United States. Clinical Infectious Diseases, v. 38, n. 3, p. 149-156, 2004.

WHITE, A. P.; WELJIE, A. M.; APEL, D.; et al. A global metabolic shift is linked to Salmonella multicellular development. PLoS ONE, v. 5, n. 7, e11814, 2010.

WHITE, A. P.; GIBSON, D. L.; KIM, W.; et al. Thin aggregative fimbriae and cellulose enhance long-term survival and persistence of Salmonella. Journal of Bacteriology, v. 188, p. 32193227, 2006.

ZAKIKHANY, K.; HARRINGTON, C. R.; NIMTZ, M.; et al. Unphosphorylated CsgD controls biofilm formation in Salmonella enterica serovar Typhimurium. Molecular Microbiology, $v$. 77, n. 3, p. 771-786, 2010.

ZOGAJ, X.; NIMTZ, M.; ROHDE, M.; et al. The multicellular morphotypes of Salmonella Typhimurium and Escherichia coli produce cellulose as the second component of the extracellular matrix. Molecular Microbiology, v. 39, p. 1452-1463, 2001.

Autor para correspondência:

Camile Milan.

Campus Universitário Capão do Leão. Prédio 34. Universidade Federal de Pelotas. Capão do Leão (RS) Brasil. cami_milan@hotmail.com 